\title{
Forest aesthetic indicators in sustainable forest management standards
}

\begin{tabular}{|r|l|}
\hline Journal: & Canadian Journal of Forest Research \\
\hline Manuscript ID & cjfr-2016-0365.R1 \\
\hline Manuscript Type: & Article \\
\hline Date Submitted by the Author: & 15-Nov-2016 \\
\hline Complete List of Authors: & $\begin{array}{l}\text { Lim, Sang Seop; Korea Forest Service, Eastern Regional Office of Forest } \\
\text { Service } \\
\text { Innes, John; University of British Columbia }\end{array}$ \\
\hline Keyword: & $\begin{array}{l}\text { Sustainable Forest Management, Forest Aesthetics, Indicator developing, } \\
\text { Forest standard, Delphi survey }\end{array}$ \\
\hline
\end{tabular}


1 Forest aesthetic indicators in sustainable forest management standards

\section{Sang Seop Lim}

3 Eastern Regional Office of Forest Service, Korea Forest Service

4 Address: 57-14, Jonghabundongjang-gil, Gangneung-si, Gangwon-do, Republic of Korea

$5 \quad$ E-mail address: sangseoplim@gmail.com

6

\section{John L. Innes}

8 Faculty of Forestry, University of British Columbia

9 Address: 2424 Main Mall, Vancouver, British Columbia, V6T 1Z4, Canada

10 Tel.: +1 604822 6761; Fax: +1 6048229106

11 E-mail address: john.innes@ubc.ca 


\section{Abstract}

2 Sustainable forest management (SFM) standards have been criticized for their lack of

3 aesthetic indicators, which some consider to be an important social component of forestry.

4 To provide a basis for the inclusion of aesthetic indicators in SFM frameworks, we used

5 Delphi techniques to survey the beliefs and opinions of SFM and aesthetic experts. The

6 three major reasons provided for the lack of aesthetic indicators were: a lack of aesthetic

7 training amongst those designing criteria and indicators; a bias against aesthetics, which

8 are often considered to be highly subjective; and the general omission of people with

9 knowledge of aesthetics during the development of SFM standards. Based on the

10 responses, we present 10 possible aesthetic indicators appropriate for international SFM

11 standards, including 8 quantitative and 2 qualitative indicators. We also provide 18 other

12 potential aesthetic indicators, which can be applied at various scales of SFM, ranging

13 from local to national. These results should provide guidance to groups developing and

14 revising criteria and indicators of sustainable forest management at various scales, from

15 local to international.

\section{Key words}

20 Sustainable Forest Management, Forest Aesthetics, Indicator Developing, Forest

21 Standard, Delphi Survey 


\section{Introduction}

2 All forest services are associated not only with satisfying basic human needs, such as

3 commodity production in forests, but also with higher-level social and cultural necessities

4 (Brown et al. 1987), such as forest aesthetic values. Forest aesthetics are considered

5 important not only for forest management but also for quality of life (Sheppard et al.

6 2004), as the public has progressively demanded more parks, scenic drives and better

7 housing locations (MEA 2005). As foresters were increasingly required to consider

8 aesthetic values, accordingly many studies of the aesthetics of forestry have been

9 conducted. Ribe (1989), for example, surveyed and analyzed more than 170 research

10 projects, dividing them into 17 topics such as inter-group preference, tree size and

11 aesthetics, management programs and so on. The large number of studies of forest

12 aesthetics might suggest that researchers should have addressed the social conflicts

13 between forest aesthetics and other forest values, especially timber products, and they

14 have certainly provided forest managers with a basis for enhancing scenic beauty in forest

15 management. The social concerns of the public related to scenic beauty have also

16 informed research on visual landscape quality assessment and the methods of systematic

17 scenery management in the late 20th century (Daniel 2001; Eroglu \& Acar 2011; Picard

18 \& Sheppard 2001a; 2001b; Roth \& Grühn 2010).

19 However, although there has been a surprising amount of research done on forest

20 aesthetics as a result of social concerns, current sustainable forest management (SFM)

21 frameworks have still been criticized for their lack of social and aesthetic criteria and

22 indicators (C\&I) (Gough et al. 2008; MCPFE 2002; Meitner et al. 2006; MP 1999;

23 Sheppard et al. 2004). Human activities impact significantly on forests (Rapport et al. 
1 1998; Vitousek et al. 1997), and therefore, SFM should meet both social needs and

2 ecological values (Brown et al. 1987; Costanza and Patten 1995; Norton 1992; Patel et al.

3 1999; Toman and Ashton 1996). Consequently, social and aesthetic values should be

4 monitored and sustained as a part of SFM, and C\&I associated with social and aesthetic

5 values must be included in SFM standards (Bengston 1994; Hunt \& Haider 2001;

6 Sheppard et al. 2006).

7 Since sustainability became an important paradigm in forest management, many

8 SFM standards and C\&I schemes have been created. SFM standards can be classified into

9 international, national and local levels based on the spatial scale of their application.

10 National SFM standards have a strong impact on the local standards in their countries

11 (McDonald and Lane 2004), and the national SFM standards, in turn, are usually strongly

12 influenced by international SFM standards (Georgiadis and Cooper 2007). For example,

13 the UK Forestry Standard clearly states that it is linked to the Helsinki Guidelines and

14 Pan-European C\&I (Forestry Commission 2004), and in 2003 the Canadian Council of

15 Forest Ministers modified the national C\&I for Canada according to the framework of the

16 Montreal Process (Hickey and Innes 2008). Countries participating in the international

17 SFM standards periodically publish their national reports based on the C\&I proposed

18 within the international SFM standards. As these national standards are also models for

19 local standards, any problems or omissions in the international standards are likely to be

20 reflected in the national and local standards.

21 Around 150 countries participate in international SFM processes (Wijewardana

22 2008). For example, the Montreal Process has 12 member countries, representing

23 approximately $60 \%$ of all the Earth's forests, and there are approximately 40 European 
1 countries in the parallel Pan-European Forest Process (Mayer 2000). Although these

2 international standards have important effects on the definition of SFM in participating

3 countries, they have been criticized for their lack of indicators directly related to social

4 aspects of SFM, especially scenic beauty (Harshaw et al. 2007; Sheppard et al. 2004) and

5 for the dominance of ecological indicators (Gough et al. 2008). These criticisms have

6 arisen because of the widespread acceptance that SFM must include an appropriate

7 balance between ecological, economic and social concerns (Bass 2001; Ferretti 1997).

8 Although some jurisdictions, such as the UK, the USA, and British Columbia in Canada,

9 have developed systematic visual management procedures, these are rarely reflected in

10 SFM standards or their associated C\&I. This problem is evident not only in the C\&I

11 published by the Montreal Process and the Pan-European Forest Process but also in the

12 SFM standards of the participating countries. For example, there are no or few data

13 related to forest aesthetic values in the recent national SFM reports produced by countries,

14 such as Australia, Canada, New Zealand, Japan, Republic of Korea (Korea), and the

15 United States (See CNR 2016; JFA 2009; KFS 2014; MARF 2009; MPIGA 2008;

16 NZMAF 2014; USDA 2010). This may reflect a widespread belief that there is no proper

17 means to measure and monitor the status of forest scenic beauty within the SFM

18 frameworks already in place. Although Meitner et al. (2006) have developed indicators of

19 scenic beauty for use at a local level, such indicators have not been adopted in any of the

20 international standards. However, without such indicators, claims of having achieved

21 sustainable forest management holistically at a national scale must be interpreted with

22 caution (Hickey and Innes 2005). 
1 In this study, we explored the reasons for the lack of aesthetic indicators and

2 whether or not there is a need for them. Based on this information, we developed specific

3 indicators for forest aesthetic values that could be incorporated into international SFM

4 standards. We used the term 'forest aesthetics' to mean scenic beauty or visual beauty,

5 although aesthetics can be more broadly defined as 'a set of principles concerned with the

6 nature and appreciation of beauty' (Oxforddictionaries 2016), and a wider definition of

7 aesthetics would also contain aesthetic features perceivable by other senses such as

8 sounds and smells, rather than sight alone. In the Delphi survey, we also supplemented

9 the meaning of the term 'forest aesthetics' by using phrases such as 'visually important

10 forests', 'forest managed to protect scenery' and 'visually sensitive areas' in the

11 questionnaire in other to clarify what we meant by the term.

12 In examining the lack of and need for aesthetic indicators in current international

13 SFM standards, we obtained perspectives from two expert panel groups: the Montreal

14 Process Working Group and a group of experts in forest aesthetics and/or visual resource

15 management. To develop specific forest aesthetic indicators, we conducted Delphi

16 surveys with these two panel groups, consisting of two rounds of questionnaires. We

17 extended the number of potential indicators through expert group consultations, and

18 evaluated the applicability of the indicators to international SFM standards using a five-

19 category rating. We believe that these results should contribute to enhancing the aesthetic

20 indicators in current international SFM standards, and through this should help improve

21 national and local SFM standards.

\section{Materials and methods}




\section{1. Delphi survey}

2 A Delphi survey was administered to assess the current status of aesthetic indicators

3 within SFM standards and to develop if necessary new forest aesthetic indicators

4 applicable to SFM standards. The Delphi technique is an iterative multi-stage process,

5 designed to collect knowledge, experiences and opinions of experts, thereby enabling us

6 to make effective decisions about issues such as creating and refining aesthetic indicators,

7 especially when there is an information deficit (Hasson et al. 2000; Miller 2002). The

8 technique is well-established in the field of indicator development. Mendoza and Prabhu

9 (2000) employed this method in assessing various indicators at a local level, and Miller

10 (2002) conducted a two-round Delphi survey on the development of indicators of

11 sustainable tourism. Wolfslehner et al. (2005) employed a national Delphi survey to rate

1243 indicators in Austria based on the Pan-European guidelines for SFM. Although

13 Georgiadis and Cooper (2007) did not adopt the Delphi method, they utilized experts'

14 judgements in assessing the indicators that they initially developed for national SFM C\&I.

15 These previous studies demonstrate that the knowledge, experiences and judgement of

16 experts can play an important role in the creation and evaluation of indicators, especially

17 at the initial stage of indicator development. Although Mendoza and Prabhu (2000) and

18 Schmidt (1997) reported that the nominal group technique with an atmosphere of open

19 dialogue might be more suitable in terms of consistency and statistical support, we

20 considered that the Delphi technique was the most appropriate method because the expert

21 panels that we selected were drawn from experts worldwide. In addition, the Delphi

22 technique seemed to be suitable for this research in view of the lack of previous research

23 in this area. 
1 In this survey, we first developed an initial set of 12 aesthetic indicators by

2 reviewing current national and international standards and previous studies. This review

3 also enabled the development of a questionnaire that we administered to two expert

4 panels: the Montreal Process Working Group (MPWG) and a group of experts in forest

5 aesthetics (AEG) identified from the published literature. In the first round survey, we

6 asked both groups to rate the initial set of 12 aesthetic indicators. The objective was to

7 analyze the applicability of the indicators to SFM standards. In addition, the experts were

8 invited to suggest any other possible aesthetic indicators. We also asked the expert to

9 suggest reasons why only a few aesthetic indicators had been included in current SFM

10 standards.

11 Based on the results of the first round survey, a second questionnaire was

12 developed. This questionnaire presented the summary of the first round survey results and

13 required respondents to indicate their opinions on the results of the first round. For newly

14 proposed aesthetic indicators (arising from the suggestions made in the first round),

15 respondents were asked to rate the indicators using the same categories as used in the first

16 round, and to indicate which level(s) of SFM (international, national, regional and forest

17 management unit levels) is(are) appropriate to each indicator. This latter task included

18 both the initial indicator set and those proposed by the first-round participants. Only two

19 rounds were completed due to the low response rate in the second round.

\section{2. Expert panels}

22 We selected two groups of experts to respond to the Delphi survey. The first group

23 consisted of 25 people from the Montreal Process Working Group (MPWG). These are 
1 individuals who have played a major role in developing and improving the C\&I used in

2 the Montreal Process. The list of participants was derived from the participant list of the

3 20th Montreal Process Working Group meeting held in Jeju, Republic of Korea, in 2009.

4 The other group comprised 25 people who had either written on aesthetic indicators or

5 had worked for their governments as specialists or researchers associated with visual

6 resource management. The list of the experts in this group was derived through an

7 internet web search. The two groups were selected to provide a general comparison

8 between individuals involved and not involved in the development of SFM frameworks.

9 We sent initial contact letters by email to the 50 experts to explain the purpose of the

10 survey and to detail our expectations. Then, the questionnaire and consent form were sent

11 by email for the first round survey.

\section{3. Questionnaires}

\section{3.1. First round questionnaire}

15 The first-round questionnaire consisted of four parts: (1) rating of an initial aesthetic

16 indicator set, (2) suggestions for other possible aesthetic indicators, (3) suggested reasons

17 for the lack of aesthetic indicators in the present international SFM standards, and (4)

18 information about the respondents. The questionnaire also included an explanation of the

19 terminology used and bibliographic references referred to in the survey.

20 To develop the initial set of 12 aesthetic indicators (IAI, See Table 1), eight

21 indicators were first drafted based on Meitner et al. (2006) and existing national and

22 international SFM C\&I, such as the Montreal Process (1999), the Pan-European Forest

23 Process (MCPFE 2002), the UK Forestry Standard (Forestry Commission 2004) and the 
1 Sustainable Forestry Initiative (SFI 2002). Although the Montreal Process and the Pan-

2 European Forest Process do not include direct aesthetic indicators (Harshaw et al. 2007;

3 Sheppard et al. 2004), two indirect indicators were transformed and included in the initial

4 set of aesthetic indicators (IAI 4 and 12 in Table 1).

5 We also examined other C\&I related to non-timber values. For example, the

6 indicators under Criterion 4, 'Conservation and Maintenance of Soil and Water

7 Resources', in the Montreal Process (1999) were originally aimed at monitoring artificial

8 and natural changes of soil and water, and we considered that such indicators could be

9 applicable to aesthetics. As a result, two further indicators related to human-caused and

10 natural changes of visual qualities were added (IAI 7 and 8 in Table 1). In addition, two

11 indicators (IAI 5 and 6 in Table 1) concerning the area of forest land managed for scenic

12 protection and the area of land converted from non-forest to forest to protect scenic

13 values were added. This resulted in 12 potential indicators being included in the initial set

14 of aesthetic indicators to be rated by the respondents.

15 To enable the panel to understand easily the features of the aesthetic indicators,

16 they were divided into four categories, as suggested in other attempts to develop social

17 indicators (Harshaw et al. 2007; Sheppard et al. 2004; Sheppard 2003): (1) procedural,

18 (2) direct outcome-based, (3) perceptions or satisfaction and (4) capacity and knowledge

19 indicators. This part of the questionnaire required the panels to rate each aesthetic

20 indicator on a 5-interval scale (low 1 to high 5) according to five rating categories

21 (Harshaw et al. 2007, See Table 2): relevancy, credibility, measurability, cost-

22 effectiveness and connectedness to forestry. The respondents were asked to explain the

23 reasons for their chosen ratings. 
Table 1.

Table 2.

In the second part, the questionnaire requested respondents to recommend other aesthetic indicators based on their own experiences, knowledge and studies. As the

7 respondents were the experts in either SFM C\&I or forest aesthetics or both, we expected

8 that they would propose additional indicators applicable to SFM standards. In the third

9 section, we suggested four possible reasons, based on Sheppard et al. (2004), for the lack

10 of aesthetic indicators in the current SFM standards. These were: (1) a cultural bias

11 among professionals and scientists that leads to aesthetics being seen as soft or subjective,

12 (2) a lack of training in aesthetics and other social science disciplines amongst scientific

13 advisory groups and government task forces, (3) a general omission from the SFM

14 standards of people with qualifications in aesthetics, and (4) the absence of substantive

15 public input to indicator setting. The respondents were requested to choose all the reasons

16 that they considered were applicable, in addition to suggesting any other reasons. In the

17 final section, we requested general information such as age, occupation, affiliation, and

18 relevant work experience.

\section{$20 \quad 3.2$. Second-round questionnaire}

21 After the first round of surveys, we developed a second-round questionnaire consisting of

22 five parts. The first section included an introduction to the survey and an explanation of

23 terminology. In the second part, we summarized the newly proposed aesthetic indicators

24 and the reasons for their recommendations by the respondents in the first-round survey. 
1 We listed 28 possible aesthetic indicators, including the 12 initial indicators and 16 new

2 indicators proposed by the respondents. Respondents were asked to provide opinions

3 about each of the possible indicators.

4 In the third part, we summarized the results of the indicator ratings obtained in

5 round one, using bar graphs to illustrate the mean responses. Respondents were then

6 asked to provide their opinions on these results. In addition, we listed the newly proposed

7 indicators, and asked the respondents to rate these using the same categories as used in

8 the first round. As these new aesthetic indicators could be applied at several scales, we

9 asked respondents to indicate the relevant scale(s) for each of the new indicators. As

10 previously, respondents were asked to explain their ratings

11 In part four, we summarized the reasons for the lack of aesthetic indicators in

12 current SFM standards, as suggested by the respondents in the first round, and asked

13 respondents to provide their opinions on these results. Finally, we provided space for any

14 further comments about the survey, and we listed the bibliographic references that were

15 used in the questionnaire.

\section{Results}

\section{1. Panel characteristics}

19 From the 50 invitations sent out for the first round survey, we obtained 19 responses:

20 eight from the Montreal Process Working Group (MPWG) and 11 from the aesthetic

21 experts group (AEG). In round two, only nine out of 19 respondents from round one

22 replied, two from MPWG and seven from AEG. The average age of respondents was 48.7

23 years old for the MPWG and 47.6 for the AEG. On average, the respondents had about 
$1 \quad 15.6$ years of work experience for the MPWG and 15.4 years for the AEG. Respondents

2 came from nine different countries (Argentina, Canada, Chile, Japan, Korea, Norway,

3 Russia, UK, and USA). There was a diversity of professional affiliations: nine in

4 government (47.4\%), four from universities (21.1\%) and six from research institutes

$5 \quad(31.6 \%)$. All the respondents in the MPWG belonged to public organizations such as

6 government departments or national research institutes.

7 The majority of respondents in the MPWG were from forestry backgrounds or at

8 least backgrounds related to forestry. For example, their major interests were in natural

9 sciences, such as biology, ecology, and biodiversity, or were associated with social

10 sciences, such as environmental policy or the marketing of forest products. Other major

11 areas of interest included recreation, planning, timber supply modeling, GIS, monitoring

12 land use change and forest assessment. However, none expressed a strong interest in

13 forest aesthetics. In contrast, the major interests of most respondents in the AEG were

14 related to forest aesthetics, such as aesthetics, visual resource management, landscape

15 architecture or environmental perception. Others came from backgrounds in planning

16 related to recreation, public participation, urban forestry and landscape ecology.

$18 \quad$ Fig. 1.

All respondents in the MPWG had participated in the work of the Montreal

21 Process C\&I, and one respondent in this group had worked for another SFM standard, the

22 Forest Steward Council (FSC). Seven respondents had contributed to environmental or

23 ecological indicators, three to economic indicators and three to the social aspects of the

24 Montreal Process C\&I (Fig.1.a). The respondents in the AEG had participated in the 
1 development of various levels of SFM standards, including at the international, national,

2 and provincial levels, and the average number of the SFM standards that they had worked

3 on was 1.2. While five respondents in the AEG had contributed to the development of

4 ecological or environmental C\&I, nine had worked on social aspects of SFM standards

$5 \quad$ (Fig.1.b).

6

7 2. Reasons for the lack of aesthetic indicators

8 Opinions about the reasons for the lack of aesthetic indicators in current international

9 SFM C\&I are shown in Table 3. The two most important reasons were considered to be a

10 bias against indicators seen as being 'soft' or 'imprecise' and a lack of expertise in

11 aesthetic appraisal techniques amongst those developing the standards. In addition to the

12 four reasons provided to the participants by the authors, three respondents suggested that

13 'scenery management or indicators are not well developed and not applied in many

14 countries', and two respondents thought that 'it would be too expensive and restricting by

15 taking areas out of production or increasing costs'.

16 The respondents in the MPWG thought that the lack of aesthetic indicators in the

17 current international SFM standards was largely due to two reasons: 'a cultural bias

18 among professionals and scientists' and 'a lack of training in aesthetics and other social

19 science disciplines'. The absence of experts in aesthetics was suggested by one

20 respondent and the lack of public input was suggested by two respondents. Two

21 respondents provided alternative explanations. While 10 of 11 respondents in the AEG

22 agreed that 'a cultural bias among professionals and scientists' and 'a lack of training in 
1 aesthetics and other social science disciplines' were important, the other two proposed

2 reasons in the first round were also considered as important by most .

4 Table 3.

\section{3. Newly proposed aesthetic indicators}

$7 \quad$ Sixteen new aesthetic indicators (PAI) were proposed by the respondents (Table 4)

8 besides the 12 initial aesthetic indicators (IAI). Two PAI (PAI 3 and 16 in Table 4) were

9 proposed by the respondents in the MPWG. The reason for the recommendation of PAI

1016 was that 'aesthetic considerations are usually outside the professionals' scope, except

11 for a few, and should be included in current training of foresters and related professions.'

12 All the other 15 PAI, except PAI 3, were suggested by the respondents in the AEG. Five

13 PAI (PAI 4, 5, 6, 11 and 16 in Table 4) were proposed by two respondents, and the others

14 were recommended by single respondents. Significantly, PAI 16 was proposed by the

15 respondents in both the MPWG and the AEG.

\section{$17 \quad$ Table 4.}

\section{4. Evaluation of the aesthetic indicators}

20 In the first round, the panels rated the initial set of 12 aesthetic indicators (IAI) in terms

21 of relevance, credibility, measurability, cost-effectiveness and connectedness to forestry

22 (Harshaw et al. 2007; See the results of Evaluation with 5 categories from IAI 1 to IAI 12

23 in Table 5). IAI 8 (Area and/or percent of forest land with significant scenery changes as

24 a result of artificial disturbances, mean response 4.0) and IAI 3 (Area and/or percent of 
1 forest land managed to protect scenery, mean response 3.9) were rated the highest by the

2 MPWG and the AEG.

3 IAI 7 (Area and/or percent of forest land with significant scenery changes from

4 natural disturbances), IAI 12 (Studies at a sample of sites with special visual values) and

5 IAI 11 (Demonstration of sustainable forest management to the public through enhanced

6 visual treatments and by providing information) were rated the lowest and the mean

7 responses of two groups (MPWG and AEG) were 3.1, 3.2 and 3.4 respectively.

8 Contributing reasons for the low rating of these indicators by the MPWG were low cost-

9 effectiveness (IAI 7 and 12, mean responses 2.6 commonly) and low measurability (IAI

1011 , mean response 2.8). For the AEG, it was because of the low relevance (IAI 7, mean

11 response 2.3), low credibility (IAI 11, mean response 3.0) and low cost-effectiveness (IAI

1212 , mean response 3.0). The two greatest differences in mean responses between MPWG

13 and AEG were for IAI 6 (Capacity of the institutional framework to develop and maintain

14 programs to conserve aesthetically valuable forests) and IAI 4 (Capacity of the

15 institutional framework to develop and maintain programs to conserve aesthetically

16 valuable forests), mainly because of the different ratings for relevance and measurability,

17 respectively.

$19 \quad$ Table 5.

21 In the second-round survey, we also required that the respondents rate the newly

22 proposed aesthetic indicators. The results are presented in Table 5 (See the results of

23 Evaluation with 5 categories from PAI 1 to PAI 16). The respondents rated PAI 8 (Area

24 and/or percent of logged area within legally established scenic area, mean response 3.8), 
1 PAI 2 (Area and/or percent of forest land with visual landscape inventory data, mean

2 response 3.8) and PAI 4 (Proportion of the institutional framework or program being

3 achieved, mean response 3.6) highest in terms of the five rating categories although the

4 average ratings for PAI were generally lower than those of the IAI. PAI 5 (Cost per ha to

5 apply institutional framework or program to private and public sectors), PAI 3 (Area

6 and/or percent of age-class distribution and species distribution of trees) and PAI 10

7 (Willingness to pay for view protection) were rated the lowest, and their mean responses

8 were $2.4,2.6$ and 2.6 respectively. The main reason for the low ratings of the PAI 5 and

9 PAI 10 were cited as the low cost-effectiveness (mean responses 1.8, commonly), and

10 PAI 3 was rated low due to the low relevancy to forest aesthetics (mean response 1.9).

\section{5. Applicability of the possible aesthetic indicators}

13 In round two, we required the respondents to rate the appropriateness of the 28 possible

14 indicators (12 IAI and $16 \mathrm{PAI}$ ), in response to the question 'at which scale(s) can this

15 indicator be applied to SFM standards?' as some of the PAI were considered to be

16 inappropriate as national or international level indicators. In this question, multiple

17 responses were allowed, and the results are also given in Table 5 (See the results of

18 Appropriateness).

Thirteen indicators (IAI 1, 3, 4, 5, 6, 8, 9, 10, 12, PAI 2, 8, 9, and 16) were rated

21 appropriate for a national or international SFM standard (5 or more responses, selected by

22 more than $50 \%$ of respondents). IAI 1 (Existence of aesthetic considerations in harvesting

23 and forests conversions where impacts are a concern), IAI 4 (Capacity of the institutional 
1 framework to develop and maintain programs to conserve aesthetically valuable forests)

2 and PAI 2 (Area and/or percent of forest land with visual landscape inventory data) were

3 rated high (7 or more responses). However, the other fifteen indicators were not rated as

4 potential international or national aesthetic indicators.

5 At the regional level, eight indicators (IAI 6, PAI 1, 3, 5, 6, 11, 12 and 15) were

6 rated as unsuitable, and twelve indicators (IAI 1, 3, 6, 12, PAI 1, 5, 6, 10, 11, 12, 14 and

7 16) were rated low (4 or fewer responses) as FMU level aesthetic indicators. Generally,

8 the indicators that were rated high as a national or international aesthetic indicator were

9 rated low as a regional or a FMU level, but seven indicators (IAI 5, 8, 9, 10, PAI 2, 8, and

$109)$ were rated as appropriate aesthetic indicators at all levels.

\section{Discussion}

13 Respondents suggested 11 reasons for the lack of aesthetic indicators in international

14 SFM frameworks. The respondents in the MPWG regarded both (a) a cultural bias among

15 professionals and scientists who viewed aesthetics as soft or subjective, and (b) a lack of

16 training in aesthetics and other social science disciplines amongst those participating in

17 scientific advisory groups and government task forces designing criteria and indicators as

18 major reasons. Such a perspective is consistent with the declared backgrounds of the

19 MPWG participants. Their contributions to the development and revision of SFM C\&I

20 had focused on the environmental indicators more than on the social indicators, and most

21 were associated with traditional forestry or related backgrounds. The AEG suggested a

22 much more diverse set of reasons, extending the explanation provided by Sheppard

23 (2003). The results suggest that there is a need for more expertise and training in social 
1 science methods including aesthetics amongst those designing C\&I for SFM standards

2 (Beckley et al. 2002). The direct involvement of experts in forest aesthetics in the

3 creation and the revision of C\&I seems warranted.

$4 \quad$ This study suggests that there are ten aesthetic indicators that could be considered

5 for inclusion in international SFM standards (Table 6). The specific criteria that were

6 used to select the final recommended international aesthetic indicators from the IAI and

7 the PAI sets were: (1) five or more responses for a national or an international indicator;

8 (2) 3.5 or higher mean responses over the five rating categories; and (3) 3.0 or higher

9 responses for each rating category. For the first category, national indicators can also be

10 adopted as international indicators without any revision because, for example, the

11 Montreal Process requires member countries to submit periodic reports (every 5 years) on

12 the state of the forests in the countries. The Montreal Process then publishes overview

13 reports based on the country reports. The criterion 'five or more responses' was also used

14 for selecting the final aesthetic indicator set because the number of the participants in this

15 question was nine, so five indicated a majority. The second criterion ' 3.5 or higher over

16 the five rating category,' was adopted because 3.5 out of 5.0 (full score) represents a

17 rating of more than $70 \%$. The last one ' 3.0 or higher responses for each rating category'

18 was selected because it would be difficult to use a criterion to monitor the state of forests

19 if the criterion had low relevance, credibility, measurability, cost-effectiveness, or

20 connectedness to forestry.

22 Table 6. 
1 Given that the current international SFM standards have been criticized for their

2 lack of quantitative indicators (Harshaw et al. 2007; Sheppard et al. 2004), the indicators

3 presented here would enable us to monitor changes in forest aesthetic qualities more

4 precisely and effectively than hitherto with the eight quantitative indicators. In addition,

5 the procedural indicator (1. Existence of aesthetic considerations in harvesting, forests

6 conversions, or planning and forest management process where impacts are a concern)

7 and the perceptions or satisfaction indicator (8. Existence of public surveys of visual

8 impacts in visually sensitive areas) would allow us to detect changes in laws and in public

9 participation and satisfaction.

10 The response rate for the second round was $47.4 \%$ (9 out of 19$)$ based on the 19

11 responses obtained from the round-one survey, but it was only $18.0 \%$ (9 out of 50) based

12 on the 50 invitations sent out for the first-round survey. While only two responses from

13 MPWG members were obtained in the second-round survey, seven experts from AEG

14 responded. The low response rate of the MPWG members may seem to show their lack of

15 interest in forest aesthetics or may reflect their feeling that the survey might not deliver

16 useful insights, or not lead to proposals that could realistically be implemented. However,

17 we assume that it may also reflect this group's reluctance to consider new indicators at a

18 time when many countries within the Montreal Process are failing to report on many of

19 the existing indicators. Because those who participated in the surveys were all experts in

20 the field of SFM or forest aesthetics, and the Delphi survey is not a statistical survey but a

21 qualitative method, the low response rate may not be a major issue (see, for example,

22 Akins et al. 2005). However, the low response rate of the MPWG members may have had

23 an impact on the results by giving them a low reliability, and accordingly, further studies 
1 can be suggested. We were actually quite surprised by the low response rates of the

2 experts, especially given that aesthetics is a known gap in the Montreal Process SFM

3 framework and we are offering a potential remedy for this.

4 The full set of results from this study is presented in Table 5, as they may be

5 useful when developing aesthetic indicators at a local scale. In addition, as forestry

6 situations differ between countries, regions and management units, the results presented

7 in Table 5 may give some indication of the potential diversity of views about particular

8 indicators.

\section{Conclusions}

11 The current lists of criteria and indicators associated with sustainable forest

12 management are noticeably lacking in indicators related to forest aesthetics. This is an

13 important omission as the general public places considerable value on aesthetics (Lim et

14 al. 2015a). The reasons for the omission are complex, but can be related to a bias against

15 social indicators, which are often seen as being of questionable value by the natural

16 scientists who have traditionally dominated C\&I development groups, and to a lack of

17 expertise amongst those individuals in the techniques currently being used to assess forest

18 aesthetics (Lim et al. 2015b).

19 This work has revealed ten potential aesthetic indicators of sustainable forest

20 management that could be used in future C\&I schemes. These have been screened for

21 relevance by both experts in the development of C\&I schemes and experts in forest

22 aesthetics. These two groups have not previously been brought together, but the use of

23 Delphi techniques enabled their views to be consolidated into a single set of potential 
1 indicators. A number of other indicators were also identified, but these are either

2 considered to be of lesser importance, or relevant only at the scale of the forest

3 management unit (FMU). Further research might screen sub-national indicators through

4 another Delphi survey involving experts who are in the field of forest management or

5 who utilize local SFM standards. The technique could be also used to develop indicators

6 in other areas that are currently lacking in C\&I schemes, most of which relate to social

7 indicators.

8 


\section{Acknowledgement}

2 This research was funded by the Canadian Social Sciences and Humanities Research

3 Council (SSHRC) and the Government of the Republic of Korea. 


\section{References}

Akins, R.B., Tolson, H., and Cole, B.R. 2005. Stability of response characteristics of a Delphi panel: application of bootstrap data expansion. BMC medical research methodology 5, 37.

Bass, S. 2001. Working with forest stakeholders. In The forests handbook: Applying forest science for sustainable management, ed. J. Evans, Blackwell Science, Oxford, U.K. pp. 221-231.

Beckley, T., Parkins, J., and Stedman, R. 2002. Indicators of forest-dependent community sustainability: The evolution of research. Forestry Chronicle 78(5): 626-636.

Bengston, D.N. 1994. Changing forest values and ecosystem management. Society \& Natural Resources 7(6), 515-533.

Brown, B.J., Hanson, M.E., Liverman, D.M., and Merideth, R.W. 1987. Global sustainability: Toward definition. Environmental Management 11(6), 713-719.

Canada Natural Resources (CNR). 2016. The State of Canada's Forests-Annual Report 2016. Minister of Natural Resources, Ottawa, Canada.

Costanza, R., and Patten, B.C. 1995. Defining and predicting sustainability. Ecological Economics 15(3), 193-196.

Daniel, T.C. 2001. Whither scenic beauty? Visual landscape quality assessment in the 21 st century. Landscape and Urban Planning 54(1-4), 267-281.

Eroglu, E., and Acar, C. 2011. Visual landscape character of Oriental Spruce (Picea orientalis (L.) Link.) mountain forests in Turkey. Journal of Environmental Engineering and Landscape Management 19(3), 189-197.

Ferretti, M. 1997. Forest health assessment and monitoring - Issues for consideration. Environmental Monitoring and Assessment 48(1): 45-72.

Forestry Commission. 2004. The UK forestry standard. Second edition ed. UK Forestry Commission, Edinburgh, U.K.

Georgiadis, N.M., and Cooper, R.J. 2007. Development of a forest certification standard compatible with PEFC and FSC's management requirements. A case study from Greece. Forestry 80(2): 113-135.

Gough, A.D., Innes, J.L., and Allen, S.D. 2008. Development of common indicators of sustainable forest management. Ecological Indicators 8(5): 425-430.

Harshaw, H.W., Sheppard, S.R.J., and Lewis, J.L. 2007. A review and synthesis of social indicators for sustainable forest management. BC Journal of Ecosystems and Management 8(2): 17-36.

Hasson, F., Keeney, S., and McKenna, H. 2000. Research guidelines for the Delphi survey technique. Journal of Advanced Nursing 32(4): 1008-1015. 
Hickey, G.M., and Innes, J.L. 2008. Indicators for demonstrating sustainable forest management in British Columbia, Canada: An international review. Ecological Indicators 8(2): 131-140.

Hickey, G.M., and Innes, J.L. 2005. Scientific review and gap analysis of sustainable forest management criteria and indicators initiatives. FORREX, Forest Research Extension Partnership, Kamloops, British Columbia, Canada.

Hunt, L., and Haider, W. 2001. Fair and effective decision making in forest management planning. Society \& Natural Resources 14(10), 873-887.

Japan Forestry Agency (JFA). 2009. State of Japan's forests and forest management2nd country report of Japan to the Montreal Process. Japan Forestry Agency, Tokyo, Japan.

Korea Forest Service (KFS). 2014. National report on sustainable forest management in Korea 2014. Korea Forest Service, Seoul, Republic of Korea.

Lim, S.S., Innes, J.L. and Meitner, M. 2015a. Public awareness of aesthetic and forest values. Journal of Environmental Management 150(2015): 243-249.

Lim, S.S., Innes, J.L. and Sheppard, S.R.J. 2015b. Awareness of Aesthetic and other forest Values-the role of forestry knowledge and education. Society and Natural Resources 28(12): 1-15.

Mayer, P. 2000. Hot spot: Forest policy in Europe: Achievements of the MCPFE and challenges ahead. Forest Policy and Economics 1(2): 177-185.

McDonald, G.T., and Lane, M.B. 2004. Converging global indicators for sustainable forest management. Forest Policy and Economics 6(1): 63-70.

Meitner, M.J., Harshaw, H.W., Sheppard, S.R.J. and Picard, P. 2006. Criterion 9: Quality-of-life indicators, arrow innovative forest practices agreement series: Extension Note 8 of 8. BC Journal of Ecosystem Management 8: 99-105.

Mendoza, G.A., and Prabhu, R. 2000. Development of a methodology for selecting criteria and indicators of sustainable forest management: A case study on participatory assessment. Environmental Management 26(6): 659-673.

Millennium Ecosystem Assessment (MEA). 2005. Ecosystems and human well-being: Synthesis. Washington D.C.: Island Press.

Miller, G. 2001. The development of indicators for sustainable tourism: Results of a Delphi survey of tourism researchers. Tourism Management 22(4): 351-362.

Minister of Agriculture of the Russian Federation (MARF). 2009. Russian Federation national report - criteria and indicators for the conservation and sustainable management of temperate and boreal forests. Federal Forestry Agency, Moscow, Russian Federation.

Ministerial Conference on the Protection of Forests in Europe (MCPFE). 2002. Improved pan-European indicators for sustainable forest management as adopted by the MCPFE expert level meeting 7-8 October 2002. Ministerial Conference on the Protection of Forests in Europe, Vienna, Austria. 
Montreal Process. 1999. Criteria and indicators for the conservation and sustainable management of temperate and boreal forests. 2nd ed. Montreal Process Liaison Office, Ottawa, Canada.

Montreal Process Implementation Group for Australia (MPIGA). 2008. Australia's state of the forests report 2008. Bureau of Rural Sciences, Canberra, Australia.

New Zealand Ministry for Primary Industries (NZMPI). 2014. Sustainable management of New Zealand's forests -New Zealand's Third Country Report on the Montreal Process Criteria and Indicators. Ministry for Primary Industries, Wellington, New Zealand.

Norton, B. 1992. Sustainability, human welfare and ecosystem health. Environmental Values 1(2), 97-111.

Oxforddictionaries. 2016. Aesthetics [online]. Available from https://en.oxforddictionaries.com/definition/aesthetics [accessed 23 October 2016]

Patel, A., Rapport, D.J., Vanderlinden, L., and Eyles, J. 1999. Forests and societal values: Comparing scientific and public perception of forest health. The Environmentalist 19(3), 239-249.

Picard, P., and Sheppard, S.R.J. 2002a. Visual resource management in British Columbia-Part I: The effects of visual resource management on timber availability: A review of case studies and policy. BC Journal of Ecosystems and Management 1(2), 7384.

Picard, P., and Sheppard, S.R.J. 2002b. Visual resource management in British Columbia-Part II: Partial cutting in the front country: A win-win solution for short-term timber availability and aesthetics. BC Journal of Ecosystems and Management 1(2), 85102.

Rapport, D., Costanza, R., and McMichael, A. 1998. Assessing ecosystem health. Trends in Ecology \& Evolution 13(10), 397-402.

Ribe, R.G. 1989. The aesthetics of forestry: What has empirical preference research taught us? Environmental Management 13(1), 55-74.

Roth, M., and Grühn, D. 2010. Modelling visual diversity, landscape characteristics and scenic beauty as visual landscape qualities for large areas. Naturschutz und Landschaftsplanung 42(4), 115-120.

Schmidt, R.C. 1997. Managing Delphi surveys using nonparametric statistical techniques. Decision Sciences 28(3): 763-774.

Sheppard, S.R.J. 2003. Knowing a socially sustainable forest when you see one: Implications for results-based forestry. Forestry Chronicle 79(5): 865-875.

Sheppard, S.R.J., Achiam, C., and D’Eon, R.G. 2004. Aesthetics: Are we neglecting a critical issue in certification for sustainable forest management? Journal of Forestry 102(5): 6-11.

Sheppard, S.R.J., Meitner, M.J., Harshaw, H.W., Wilson, N., and Pearce, C. 2006. Public processes in sustainable forest management for the arrow forest district, \#3 in the 
sustainability project extension note series. Journal of Ecosystems and Management 7(1), 57-66.

Sustainable Forestry Initiative (SFI). 2002. 2002-2004 edition sustainable forestry initiative program. American Forest and Paper Association, Washington, D.C.

Toman, M.A., and Ashton, P.M.S. 1996. Sustainable forest ecosystems and management: A review article. Forest Science 42(3), 366-377.

United States Department of Agriculture (USDA). 2010. National report on sustainable forests - 2010. United States Department of Agriculture, Washington, D.C.

Vitousek, P.M., Mooney, H.A., Lubchenco, J., and Melillo, J.M. 1997. Human domination of earth's ecosystems. Science 277(5325), 494.

Wijewardana, D. 2008. Criteria and indicators for sustainable forest management: The road travelled and the way ahead. Ecological Indicators 8(2): 115-122.

Wolfslehner, B., Vacik, H., and Lexer, M.J. 2005. Application of the analytic network process in multi-criteria analysis of sustainable forest management. Forest Ecology and Management 207(1-2): 157-170. 
1 Table 1. Initial set of 12 aesthetic indicators (IAI) for the round-one questionnaire

Initial aesthetic indicators
IAI 1. Existence of aesthetic considerations in harvesting and forests
conversions where impacts are a concern (e.g. laws, regulations or public
participation processes etc)

IAI 2. Existence of historic and/or cultural records on visually important forests

IAI 3. Area and/or percent of forest land managed to protect scenery ${ }^{\text {a }}$

IAI 4. Capacity of the institutional framework to develop and maintain programs to conserve aesthetically valuable forests (e.g. Visual Quality Objectives)

IAI 5. Area and/or percent of forest land where silviculture is designed to protect scenery (e.g. thinning, prevention, control)

IAI 6. Area and/or percent of land conversion from non-forest to forest to protect scenery (e.g. afforestation)

IAI 7. Area and/or percent of forest land with significant scenery changes from natural disturbances (e.g. landslides, dieback, insects, fire, wind, snow and rain)

IAI 8. Area and/or percent of forest land with significant scenery changes as a result of artificial disturbances (e.g. conversion for roads, housing)

IAI 9. Area and/or percent of forest land used for timber yield that is protecting scenery by adopting alternative harvesting techniques to clear-cutting (e.g. continuous cover forestry, selective cutting, regeneration before cutting)

IAI 10. Existence of public acceptance surveys of visual impacts in visually sensitive areas

IAI 11. Demonstration of sustainable forest management to the public through enhanced visual treatments and by providing information

IAI 12. Studies at a sample of sites with special visual values

SFI 2002

Source

Forestry Commission

2004

Montreal Process 1999

MCPFE 2002

Refer to Montreal

Process 1999 (soil and water indicators)

Refer to Montreal Process 1999 (soil and water indicators)

SFI 2002

Meitner et al. 2006

Meitner et al. 2006

MCPFE 2002
2

3

${ }^{a}$ The original indicator (Montreal Process 1999) of IAI 3 is 'Extent of area by forest type in protected area categories as defined by IUCN or another classification systems,' and the definition of protected area by IUCN (International Union for Conservation of Nature) includes landscape conservation. 
1 Table 2. Rating categories for the possible aesthetic indicators

\section{Rating categories}

Relevancy: Does the indicator tell us something meaningful about social conditions, especially in terms of forest aesthetic values? Is it sensitive to change, and will it show trends over time?

Credibility: Is the indicator reliable (relatively free of factors that introduce "noise") when it comes to interpreting indicator measurements? Is it seen as valid by affected communities and grounded in their cultural worldviews?

Measurability: Is the indicator clearly defined and specific? Is it measurable at an appropriate scale and with sufficient accuracy to be useful? Is data for this indicator available?

Cost-effectiveness: Is the cost of measuring this indicator justified by the value of the information it provides?

Connectedness to forestry: Is the indicator responsive to management actions and practices? Can future indicator levels be forecasted with reasonable accuracy in relation to planned forestry activities?

2 
1 Table 3. Reasons for the absence of aesthetic indicators in current SFM standards

\begin{tabular}{|c|c|c|c|}
\hline \multirow{2}{*}{ Reasons $^{\text {a }}$} & \multicolumn{3}{|c|}{ Frequency (\%) } \\
\hline & Total & MPWG $^{\text {b }}$ & $\mathbf{A E G}{ }^{c}$ \\
\hline $\begin{array}{l}\text { Reason 1: A cultural bias among professionals and scientists that leads } \\
\text { to aesthetics being seen as soft or subjective }\end{array}$ & 28.6 & 29.4 & 22.7 \\
\hline $\begin{array}{l}\text { Reason 2: A lack of training in aesthetics and other social science } \\
\text { disciplines at all levels, from scientific advisory groups and } \\
\text { government task forces designing criteria and indicators to forest } \\
\text { managers and certification teams }\end{array}$ & 31.7 & 41.2 & 22.7 \\
\hline $\begin{array}{l}\text { Reason 3: A general omission from the SFM standards of people with } \\
\text { qualifications in aesthetics, such as landscape architects, } \\
\text { landscape foresters, and other social science professionals }\end{array}$ & 14.3 & 5.9 & 18.2 \\
\hline $\begin{array}{l}\text { Reason } 4 \text { : The absence of substantive public input to indicator setting, } \\
\text { whereby public concerns for aesthetics, for example, could be } \\
\text { actively expressed. }\end{array}$ & 9.5 & 11.8 & 13.6 \\
\hline Alternative reasons suggested by respondents & 15.9 & 11.8 & 22.7 \\
\hline Total & 100.0 & 100.0 & 100.0 \\
\hline
\end{tabular}

${ }^{a}$ Reasons 1 to 4 were provided in round-one questionnaire, and 7 alternative reasons were suggested by

3 respondents.

$4{ }^{\mathrm{b}} \mathrm{n}=8$, allowing for multiple responses

$5{ }^{\mathrm{c}} \mathrm{n}=11$, allowing for multiple responses 
1 Table 4. Newly proposed aesthetic indicators (PAI) by respondents in round-one survey

Proposed aesthetic indicators

Frequency $^{\text {a }}$

PAI 1. Existence of considerations for balance between forest scenery management and other industries or fields (e.g. tourism, recreation, timber production etc.)

PAI 2. Area and/or percent of forest land with visual landscape inventory data

PAI 3. Area and/or percent of age-class distribution and species distribution of trees

PAI 4. Proportion of the institutional framework or program being achieved (e.g. with evaluation or monitoring system)

PAI 5. Cost per ha to apply institutional framework or program to private and public sectors

PAI 6. General consistency with accepted professional (e.g. perception expert, landscape architect etc.) standards or scenic design guidelines

PAI 7. Inclusion of public perception testing in monitoring or establishment of guidelines

PAI 8. Area and/or percent of logged area within legally established scenic area

PAI 9. Percent of harvested forest in scenic areas compared to amount of regenerated and visually greened up forest

PAI 10. Willingness to pay for view protection

PAI 11. Number of public / indigenous or residents / stakeholders complaints regarding poor visual management

PAI 12. Area and/or percent of scenic forest land where logging is highly acceptable, marginally acceptable, and marginally unacceptable

PAI 13. General level of public acceptance of visual outcomes of forest management

PAI 14. Number and/or percentage of visitors that rate scenery important to their visit or reason for travel

PAI 15. Existence of the use of "Signs of Care" in the visual design or logging activities

PAI 16. Training in forest aesthetic values provided to professionals involved in forest management and design (e.g. capacity, university programs, courses, etc.)

2 a Number of recommendation by respondents ( $\mathrm{n}=19$, allowing for multiple recommendations) 
1 Table 5. Rating results of possible aesthetic indicators by experts

\begin{tabular}{|c|c|c|c|c|c|c|c|c|c|}
\hline \multirow{2}{*}{$\begin{array}{l}\text { Possible } \\
\text { aesthetic } \\
\text { indicators }{ }^{\text {a }}\end{array}$} & \multicolumn{5}{|c|}{ Evaluation with 5 categories ${ }^{\text {b }}$} & \multicolumn{4}{|c|}{ Appropriateness $^{c}$} \\
\hline & C1 & $\mathrm{C} 2$ & $\mathbf{C 3}$ & $\mathrm{C} 4$ & $\mathbf{C 5}$ & Mean & S1 & S2 & $\mathrm{S3}$ or $\mathrm{S} 4$ \\
\hline IAI 1 & 4.21 & 3.32 & 3.05 & 3.56 & 4.21 & 3.67 & 4 & 7 & 8 \\
\hline IAI 2 & 3.58 & 3.58 & 3.53 & 3.31 & 3.58 & 3.52 & 7 & 8 & 3 \\
\hline IAI 3 & 3.89 & 3.61 & 4.05 & 4.00 & 4.05 & 3.92 & 4 & 8 & 6 \\
\hline IAI 4 & 4.17 & 3.59 & 3.53 & 3.60 & 3.83 & 3.74 & 5 & 7 & 8 \\
\hline IAI 5 & 3.89 & 3.32 & 3.58 & 3.19 & 4.42 & 3.68 & 6 & 8 & 5 \\
\hline IAI 6 & 3.37 & 3.39 & 3.78 & 3.07 & 3.56 & 3.43 & 4 & 4 & 5 \\
\hline IAI 7 & 2.89 & 3.00 & 3.44 & 2.69 & 3.11 & 3.03 & 5 & 5 & 3 \\
\hline IAI 8 & 4.22 & 4.00 & 3.94 & 3.73 & 4.06 & 3.99 & 6 & 6 & 5 \\
\hline IAI 9 & 3.79 & 3.53 & 3.74 & 3.33 & 4.53 & 3.78 & 6 & 6 & 5 \\
\hline IAI 10 & 3.89 & 3.63 & 3.79 & 3.06 & 4.05 & 3.68 & 5 & 7 & 5 \\
\hline IAI 11 & 3.63 & 3.16 & 2.95 & 3.07 & 4.03 & 3.37 & 5 & 6 & 4 \\
\hline IAI 12 & 3.21 & 3.07 & 3.36 & 2.83 & 3.64 & 3.22 & 3 & 6 & 5 \\
\hline PAI 1 & 2.88 & 2.38 & 2.50 & 2.33 & 3.63 & 2.74 & 4 & 4 & 2 \\
\hline PAI 2 & 3.89 & 3.78 & 4.11 & 3.43 & 3.89 & 3.82 & 7 & 8 & 7 \\
\hline PAI 3 & 1.86 & 2.29 & 3.13 & 2.00 & 3.50 & 2.55 & 6 & 4 & 0 \\
\hline PAI 4 & 4.00 & 3.88 & 3.25 & 3.29 & 3.50 & 3.58 & 5 & 7 & 4 \\
\hline PAI 5 & 2.57 & 2.14 & 2.29 & 1.83 & 3.14 & 2.40 & 3 & 3 & 2 \\
\hline PAI 6 & 3.40 & 3.00 & 2.20 & 3.00 & 3.40 & 3.00 & 4 & 2 & 1 \\
\hline PAI 7 & 3.75 & 3.25 & 2.75 & 2.29 & 2.88 & 2.98 & 5 & 6 & 2 \\
\hline PAI 8 & 3.67 & 3.56 & 4.11 & 3.57 & 4.22 & 3.83 & 6 & 8 & 5 \\
\hline PAI 9 & 3.00 & 3.20 & 3.20 & 2.80 & 4.00 & 3.24 & 5 & 5 & 5 \\
\hline PAI 10 & 2.83 & 2.67 & 2.50 & 1.80 & 3.00 & 2.56 & 3 & 5 & 3 \\
\hline PAI 11 & 2.67 & 2.00 & 3.17 & 3.20 & 3.33 & 2.87 & 3 & 3 & 2 \\
\hline PAI 12 & 3.00 & 2.00 & 2.29 & 3.00 & 3.71 & 2.80 & 4 & 4 & 2 \\
\hline PAI 13 & 3.43 & 3.29 & 3.14 & 2.80 & 4.14 & 3.36 & 5 & 6 & 4 \\
\hline PAI 14 & 3.29 & 3.29 & 3.67 & 3.00 & 3.43 & 3.33 & 4 & 6 & 4 \\
\hline PAI 15 & 3.63 & 3.13 & 3.17 & 2.80 & 3.88 & 3.32 & 8 & 3 & 0 \\
\hline PAI 16 & 3.50 & 3.38 & 3.00 & 3.14 & 3.50 & 3.30 & 2 & 5 & 5 \\
\hline
\end{tabular}

a See Table 1 and 3 for the meaning of each IAI and PAI

${ }^{\mathbf{b}}$ Values are mean responses (1.00 to 5.00); 5 categories were relevance $(\mathrm{C} 1)$, credibility $(\mathrm{C} 2)$, measurability (C3), cost-effectiveness (C4) and connection to forestry (C5); Number of panels participating were 19

${ }^{\mathbf{c}}$ Values are numbers of respondents (0 to 9); applicability of scale were forest management unit level (S1), regional level (S2), national level (S3) and international level (S4); Number of panels participating were 9 and allowing multiple responses 
1 Table 6. Final recommended aesthetic indicators at an international SFM level and their characteristics

\begin{tabular}{|c|c|c|}
\hline Aesthetic indicators ${ }^{a}$ & Characteristics & \\
\hline $\begin{array}{l}\text { 1. Existence of aesthetic considerations in harvesting, } \\
\text { forests conversions, or planning and forest } \\
\text { management process where impacts are a concern } \\
\text { (e.g. laws, regulations, public participation processes, } \\
\text { landscape architect participation etc.) }\end{array}$ & Procedural & qualitative \\
\hline $\begin{array}{l}\text { 2. Area and/or percent of visually sensitive forest land or } \\
\text { scenic forest land being protected }\end{array}$ & direct outcome-based & quantitative \\
\hline $\begin{array}{l}\text { 3. Area and/or percent of forest land managed by } \\
\text { institutional framework or program to conserve } \\
\text { aesthetically valuable forests (e.g. Visual Landscape } \\
\text { Design, Visual Resource Management, Scenery } \\
\text { Management, Visual Quality Objectives, etc.) }\end{array}$ & direct outcome-based & quantitative \\
\hline $\begin{array}{l}\text { 4. Area and/or percent of forest land where silviculture is } \\
\text { designed to protect scenery (e.g. thinning, fire } \\
\text { prevention, insect control etc.) }\end{array}$ & direct outcome-based & quantitative \\
\hline $\begin{array}{l}\text { 5. Area and/or percent of land conversion from non- } \\
\text { forest to forest to protect scenery (e.g. afforestation } \\
\text { etc.) }\end{array}$ & direct outcome-based & quantitative \\
\hline $\begin{array}{l}\text { 6. Area and/or percent of forest land with significant } \\
\text { scenery changes as a result of artificial disturbances } \\
\text { (e.g. conversion for roads, housing etc.) }\end{array}$ & direct outcome-based & quantitative \\
\hline $\begin{array}{l}\text { 7. Area and/or percent of forest land used for timber } \\
\text { yield that is protecting scenery by adopting alternative } \\
\text { harvesting techniques to clear-cutting (e.g. continuous } \\
\text { cover forestry, selective cutting, regeneration before } \\
\text { cutting etc.) }\end{array}$ & direct outcome-based & quantitative \\
\hline $\begin{array}{l}\text { 8. Existence of public surveys of visual impacts in } \\
\text { visually sensitive areas }\end{array}$ & perceptions or satisfaction & qualitative \\
\hline $\begin{array}{l}\text { 9. Area and/or percent of forest land with visual } \\
\text { landscape inventory data }\end{array}$ & direct outcome-based & quantitative \\
\hline $\begin{array}{l}\text { 10. Area and/or percent of logged area within legally } \\
\text { established scenic area }\end{array}$ & direct outcome-based & quantitative \\
\hline \multirow[b]{2}{*}{ Total 10 aesthetic indicators } & 1 procedural & 2 qualitative \\
\hline & $\begin{array}{l}1 \text { perceptions or satisfaction } \\
8 \text { direct outcome-based }\end{array}$ & 8 quantitative \\
\hline
\end{tabular}

${ }^{a}$ Some indicators were rephrased based on the opinions of panels and are therefore wording may differ from the IAI and PAI in Table 5. 

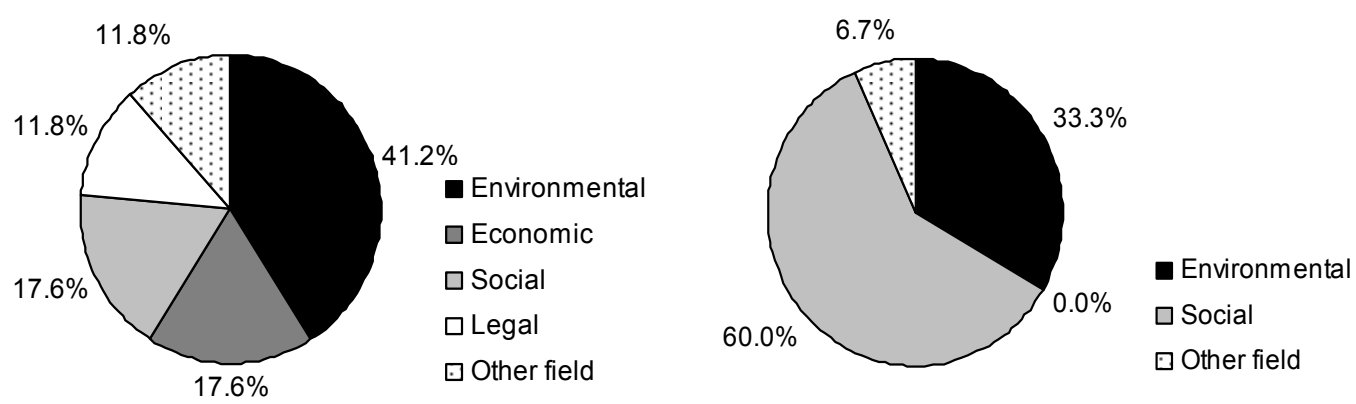